\title{
Rice Husk Waste as an Exothermic Material for a Riser Sleeve for Steel Casting
}

\author{
Dewi Idamayanti ${ }^{1 *}$, Wiwik Purwadi ${ }^{1}$, Beny Bandanadjaja ${ }^{1}$, Rafidan Triadji $^{1}$ \\ ${ }^{1}$ Department of Foundry Engineering, Politeknik Manufaktur Bandung, Jl. Kanayakan No.21 Bandung 40135, \\ West Java, Indonesia
}

\begin{abstract}
This research examines the suitability of rice husk waste as an exothermic material for a riser sleeve for use in steel casting production. Exothermic sleeves are used in the steel casting process to compensate for shrinkage of the steel during solidification. Commonly, the exothermic sleeve consists of fuel materials, fillers, and binders. Rice husk waste has potential for use as a fuel material in the exothermic sleeve due to its high calorific value. For this study, rice husk waste was ground to gain a particle size of 60 mesh and then mixed with organic binders of $12 \mathrm{wt} \%, 15 \mathrm{wt} \%$, and $18 \mathrm{wt} \%$. A H-sleeve was then formed by hand pressing, followed by drying. A series of quantitative tests were carried out to analyze the performance of the rice husk as an exothermic material. These include measurement of modulus extension factor (MEF) and the cooling rate of the steel casting within the liquidus-solidus temperature range. The test results show that the rice husk sleeve mixed with $12 \mathrm{wt} \%$ of binder extended the solidification time from 273 seconds to up to 511 seconds within the desired temperature range. Furthermore, the best MEF of 1.69 was achieved using the rice husk riser sleeve. This meets the standard MEF value of an exothermic sleeve.
\end{abstract}

Keywords: Exothermic sleeve; Modulus extension factor; Rice husk; Riser sleeve; Steel casting

\section{Introduction}

Exothermic riser sleeves are feeding aids used in steel casting to prevent the molten steel from shrinking during solidification. They perform better than silica sand risers (conventional risers) in increasing feeding efficiency and minimizing the riser size (Brown, 2000; Miki, 2002). One riser sleeve manufacturer reports that the use of an exothermic riser sleeve can enhance the casting yield by 74.47-91.80\% (Schäfer, 2011). According to many references (Auderheide et al., 1999; Miki, 2002; Schäfer, 2011), exothermic riser sleeves consist of fuels (i.e., oxidizable metals or exothermic materials), fillers (i.e., sand or metal oxides), and binders (i.e., resin or water glass). In order for an exothermic riser sleeve to produce a high casting yield, certain parameters must be considered, such as the heat resistance of the fuel material in the exothermic sleeve, which should readily ignite at $600^{\circ} \mathrm{C}$ (Williams et al., 2015; Dafiqurrohman et al., 2016); the density of the exothermic sleeve, which should be low as porosity produces higher insulation (Miki, 2002); and the ash content after the material is burned (Rao, 2013). These properties are required to keep the retardation of temperature fall during steel 
solidification. In our previous studies (Idamayanti et al., 2015; Purwadi et al., 2016), we investigated an exothermic riser sleeve manufactured from aluminium slag and red mud waste. The results of these studies confirmed that the synergy of these materials resulted in excellent characteristics due to their exothermic and insulating behavior.

However, our previous studies revealed several problems, including limited raw materials and a complicated sleeve fabrication process. To solve these problems, substitute materials were studied based on their thermal properties. One study reported on an experiment in which rice husk was used as the primary material to produce a top riser sleeve to prevent heat loss from the mold (Rao, 2013). This showed the potential of rice husk for use in a riser sleeve. Currently, rice husk is not widely used in the foundry industry, despite its abundance as biomass waste in Indonesia (Gibran et al., 2018). It is a source of renewable energy and, due to its high calorific value (Lim et al., 2012), is promising as an exothermic material. Thus, this study aimed to utilize rice husk waste as a material for an exothermic riser sleeve. Rice husk has a remarkably higher heating value $(15.84 \mathrm{MJ} / \mathrm{kg}$ ) (Lim et al., 2012) than commercial exothermic sleeves (250-850 kJ/kg) (Williams et al., 2015). Burned rice husk produces combustion residues that contain $\mathrm{SiO}_{2}(91.42 \%), \mathrm{K}_{2} \mathrm{O}$ (3.71\%), $\mathrm{CaO}$ (3.21\%), $\mathrm{Al}_{2} \mathrm{O}_{3}(0.78 \%)$, and small amounts of other metal oxides (Maiti et al., 2006), all of which can act as insulators. As well as being affordable and having slow oxidation properties, rice husk is one of the carbonaceous materials with anti-piping characteristics (Rao, 2013). Based on previous studies, it can be concluded that rice husk is a potential material for exothermic sleeves with its excellent physical properties (Maiti et al., 2006), effective insulating potential due to the amorphous structure of residual silica, and the high porosity of its ash residues (Wang et al., 2016a); (Tiwari and Pradhan, 2017). It is easy to form into briquettes with a low binder of 2-4\% (Maiti et al., 2006) and is an eco-friendly product with very low emissions (Unrean et al., 2018).

Hence, this research focuses on the use of rice husk waste as an exothermic material for a riser sleeve in steel casting. Its suitability as a riser sleeve was determined quantitatively by testing the modulus extension factor (MEF) and measuring the cooling rate to observe the thermal behavior of the rice husk sleeve. Furthermore, the simulation was calculated to predict its feeding efficiency in steel casting. The physical properties of the rice husk sleeve, such as its bulk density and compressive strength, were also investigated.

\section{Methods}

\subsection{Materials}

The rice husk sleeve was formed by mixing rice husk waste, collected from a local rice mill, with acetate polymer, which is an organic binder made of technical grade material. To identify the performance of the rice husk sleeve in the feeding system, GX60Cr15, a high alloy steel, was selected. An elemental analysis of the GX60Cr15 alloy was conducted using an optical emission spectrometer (OES, research grade ARL 4360). The results are shown in Table 1.

The rice husk particles were prepared by milling and sieving to reduce and homogenize the size of the rice husk feedstock to within a range of 40 to 60 mesh. The higher heat value (HHV) of rice husk waste and a commercial sleeve (KALMINEX 2000) were measured using a bomb calorimeter and are shown in Table 2 . 
Table 1 Elemental analysis of GX60Cr15

\begin{tabular}{cc}
\hline Elements & $\%$ \\
\hline $\mathrm{C}$ & 0.638 \\
$\mathrm{Cr}$ & 14.925 \\
$\mathrm{Mn}$ & 0.618 \\
$\mathrm{Si}$ & 1.018 \\
$\mathrm{Mo}$ & 0.125 \\
$\mathrm{Ni}$ & 2.588 \\
$\mathrm{~V}$ & 0.060 \\
$\mathrm{P}$ & 0.025 \\
$\mathrm{Fe}$ & balance \\
\hline
\end{tabular}

Table 2 Higher heat value (HHV) of materials

\begin{tabular}{lc}
\hline \multicolumn{1}{c}{ Materials } & HHV (MJ/kg) \\
\hline Rice husk & 15.3 \\
KALMINEX 2000 & 11.3 \\
\hline
\end{tabular}

\subsection{Fabrication of Rice Husk Sleeve}

The rice husk was mixed homogeneously with various amount of organic binder: $12 \%$ wt, $15 \%$ wt, and $18 \%$ wt. The mixture was molded and compacted by manual (hand) pressing to form a cylinder sleeve (H-sleeve type), as shown in Figure 1.

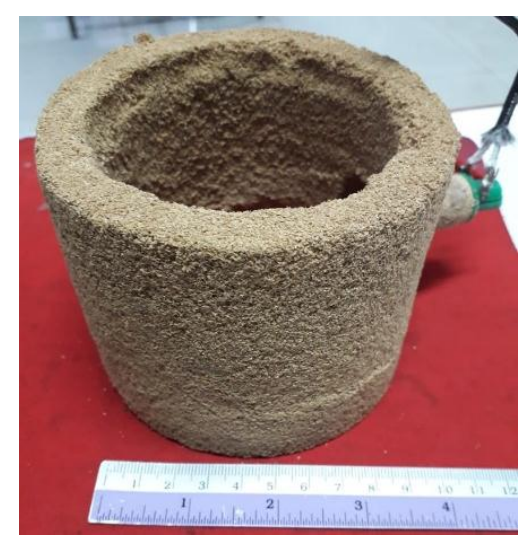

Figure 1 Rice husk sleeve

The sleeve dimensions used for the observation were $80 \mathrm{~mm}$ in diameter, $15 \mathrm{~mm}$ in thickness, and $80 \mathrm{~mm}$ in height, with the modulus of the sleeve set accordingly to $1.38 \mathrm{~cm}$. The last step was to dry the sleeve at $110^{\circ} \mathrm{C}$ for 1 hour.

\subsection{Rice Husk Sleeve Characterizations}

Characterizations were performed to identify the quality of the sleeve. Several characteristics of the rice husk sleeve were determined by referring to the standard specifications of IS 15865:2009 (The Foundry and Steel Castings Sectional Committee, 2009).

\subsubsection{Compressive strength}

The compressive strength of a sleeve should be $5.0 \mathrm{~kg} / \mathrm{cm}^{2}$ or higher. The whole sleeve was tested in compression mode until it fractured. The compressive strength was obtained by dividing the highest load of the sleeve by its average cross-sectional area. The compressive strength not only indicates the sleeve's resistance against the compressive 
load, but also other properties associated with this load type, such as formability and stability during storage. The compressive strength was also used to determine the minimum binder content.

\subsubsection{Bulk density}

The bulk density of the sleeve was obtained by dividing the weight of the sleeve by its volume. The bulk density of the rice husk sleeve was in the range of $0.3-0.4 \mathrm{~g} / \mathrm{cm}^{3}$. The degree of porosity, which is related to the bulk density of the sleeve, increases its insulation.

\subsubsection{Cooling rate measurement}

A thermocouple was installed in the center of the sleeve and attached to a data logger, which recorded the cooling temperature for 30 minutes. The experimental layout is illustrated in Figure 2. The data recording was carried out during the liquid state of the material ranging, from the pouring temperature to the liquidus temperature of GX60Cr15 $\left(1340^{\circ} \mathrm{C}\right)$, which was then established as a working temperature range of the sleeve.

The solidification temperature of GX60Cr15 casting was measured for both the rice husk sleeve and the sand riser, while the KALMINEX sleeve was used as a reference sleeve.

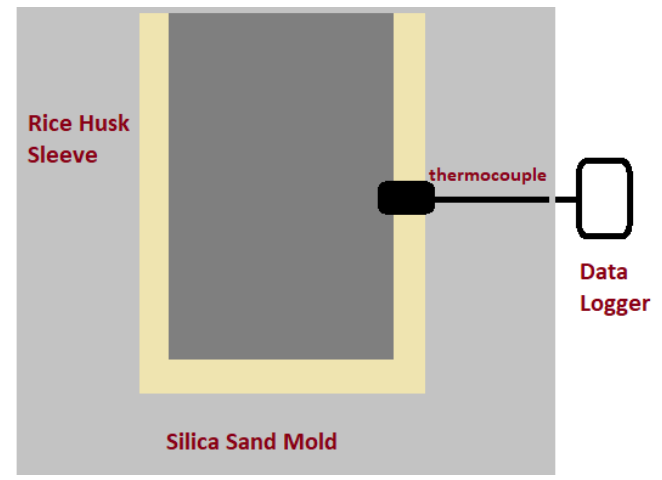

(a)

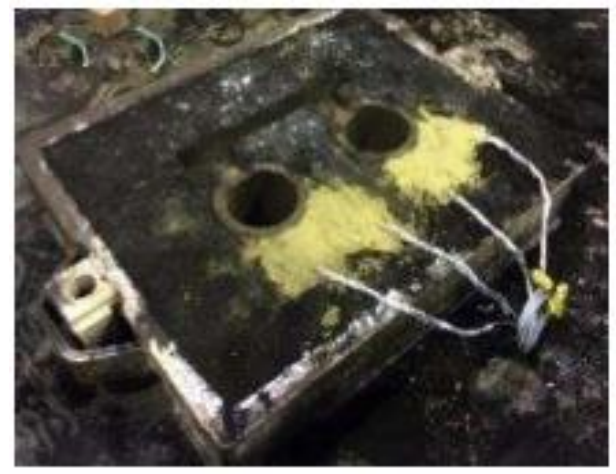

(b)

Figure 2 The layout for temperature measurement: (a) cross-section view; (b) top view

\subsubsection{Modulus extension factor (MEF)}

The ratio of a sand riser modulus to the sleeve modulus at the same retardation time is expressed as the MEF. The recommended MEF values by size are shown in Table 3 (The Foundry and Steel Castings Sectional Committee, 2009).

Table 3 The MEF criteria of a sleeve

\begin{tabular}{lcc}
\hline & \multicolumn{2}{c}{ Minimum MEF } \\
\cline { 2 - 3 } & $\begin{array}{c}\text { Exothermic } \\
\text { and insulating sleeves }\end{array}$ & $\begin{array}{c}\text { Insulating } \\
\text { sleeve }\end{array}$ \\
\hline Up to $150 \mathrm{~mm}$ diameter & 1.60 & 1.45 \\
160 to $225 \mathrm{~mm}$ diameter & 1.45 & 1.30 \\
250 to $300 \mathrm{~mm}$ diameter & 1.40 & 1.30 \\
325 to $400 \mathrm{~mm}$ diameter & 1.30 & 1.20 \\
425 to $500 \mathrm{~mm}$ diameter & 1.30 & 1.20 \\
$525 \mathrm{~mm}$ and above & 1.30 & 1.20 \\
\hline
\end{tabular}

\section{Results and Discussion}

\subsection{Rice Husk as the Main Material of the Sleeve}

Table 2 shows that the rice husk released heat energy to up to $15.3 \mathrm{MJ} / \mathrm{kg}$. When the rice husk was applied as a riser sleeve, it resembled a pyrolysis reaction which burned at 
$250-600^{\circ} \mathrm{C}$ (Wang et al., 2016a). The reaction continued while the molten steel (approximately $1500^{\circ} \mathrm{C}$ ) was poured, which led to the release of a considerable amount of heat and a subsequent extension of the solidification time. The first stage of the exothermic reaction in common biomass is hemicellulose decomposition, which released $40-280 \mathrm{~kJ} / \mathrm{kg}$ of energy (Bates et al., 2013). The pyrolysis of rice husk, represented by the reaction scheme in Equation 1, is a thermochemical decomposition in which biomass organics are heated at high temperatures in the absence of oxygen and, therefore, decompose into solid carbon and volatile matter (Wang et al., 2016b; Quispe et al., 2017).

$$
\text { Rice husk } \rightarrow \text { solid residue + volatile and gas (Said et al., 2014) }
$$

The temperature of the pyrolysis process influences the pyrolysis product. At $1200^{\circ} \mathrm{C}$ or higher, the mass fraction of pyrolysis gas (volatile matter) is higher than that of rice husk char and tar (Wang et al., 2016b). Xinyu Wang et al. concluded that pyrolysis gas is mostly released within 6 minutes (Wang et al., 2016b). The higher the temperature, the more gas is produced. Furthermore, $\mathrm{CH}_{4}$ and $\mathrm{CO}$ gases are predominantly formed when rice husk sleeve is in direct contact with molten steel at $1500^{\circ} \mathrm{C}$.

Furthermore, a previous study reported the measurement of the heat released during rice husk degradation (pyrolysis) using differential scanning calorimetry (Said et al., 2014). The results showed that there are several steps or zones in the pyrolysis of rice husk, namely the decomposition zone, the drying zone, the devolatilizing zone, and the char degradation zone. In the drying zone, the amount of heat absorbed by moisture is 161.5 $\mathrm{kJ} / \mathrm{kg}$, which is known as the endothermic process. In the devolatilizing zone, the released energy is $4437 \mathrm{~kJ} / \mathrm{kg}$, and in the char degradation zone, the energy absorbed is $313 \mathrm{~kJ} / \mathrm{kg}$ (Said et al., 2014). The total energy involved in the pyrolysis of rice husk is determined as enthalpy decomposition energy (which is confirmed as the heating value). The mechanism of thermal degradation of rice husk has been thoroughly investigated and proves that rice husk has significant potential for use as the primary material in exothermic sleeves with a heat value that is higher than that of commercial sleeves.

\subsection{Characterization of the Rice Husk Sleeve}

\subsubsection{Compression strength}

Based on IS 15865:2009, the compression strength should be $5.0 \mathrm{~kg} / \mathrm{cm}^{2}$ or higher and, for that purpose, is controlled by adjusting the binder content. This study uses acetate polymer binder to bind the rice husk particles in various mass fractions of $12 \mathrm{wt} \%, 15 \mathrm{wt} \%$, and $18 \mathrm{wt} \%$. As Figure 3 shows, the rice husk sleeve had a compression strength of 6.67 $\mathrm{kg} / \mathrm{cm}^{2}, 11.02 \mathrm{~kg} / \mathrm{cm}^{2}$, and $16.26 \mathrm{~kg} / \mathrm{cm}^{2}$, respectively. Subsequently, the rice husk sleeve was formed using a binder content of $12 \mathrm{wt} \%, 15 \mathrm{wt} \%$, and $18 \mathrm{wt} \%$. The higher the binder content, the better the formability of the sleeve. 
Compressive strength $\left(\mathrm{Kg} / \mathrm{cm}^{2}\right)$

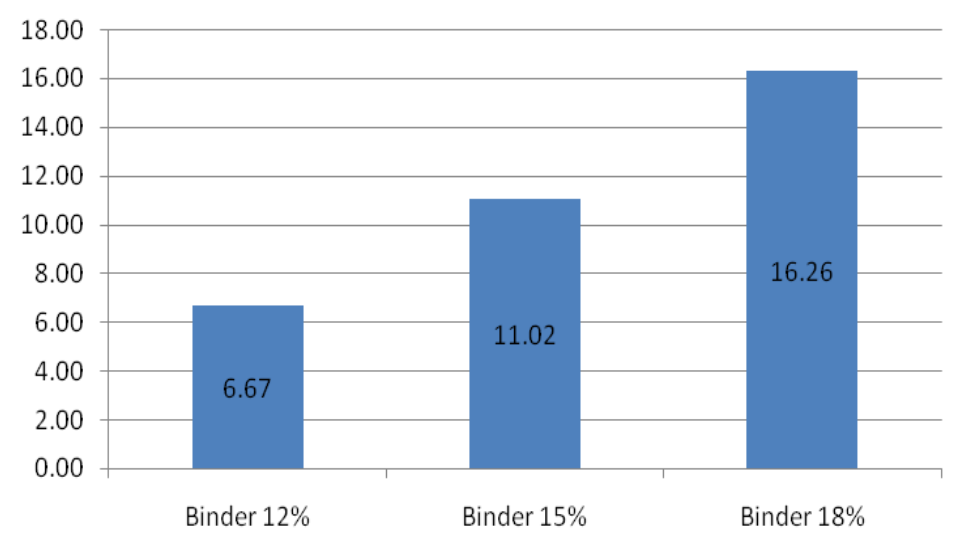

Figure 3 The compressive strength of the rice husk sleeve

\subsection{Thermal Behavior of the Rice Husk Sleeve}

The effectiveness of an exothermic sleeve is determined by the duration necessary for the sleeve to retard the solidification of the steel in the riser. Furthermore, heat released by the exothermic reaction can delay the formation of a solid shell in the early stages of steel solidification (Midea et al., 2007). The burning of the sleeve involves several stages take: ignition, combustion, time to reach maximum temperature, and insulation.

The temperature of the GX60Cr15 casting was measured over 30 minutes. As shown in Figure 4 , the ideal temperature range of rice husk sleeve was determined as $1340^{\circ} \mathrm{C}$ (liquidus temperature) or above.

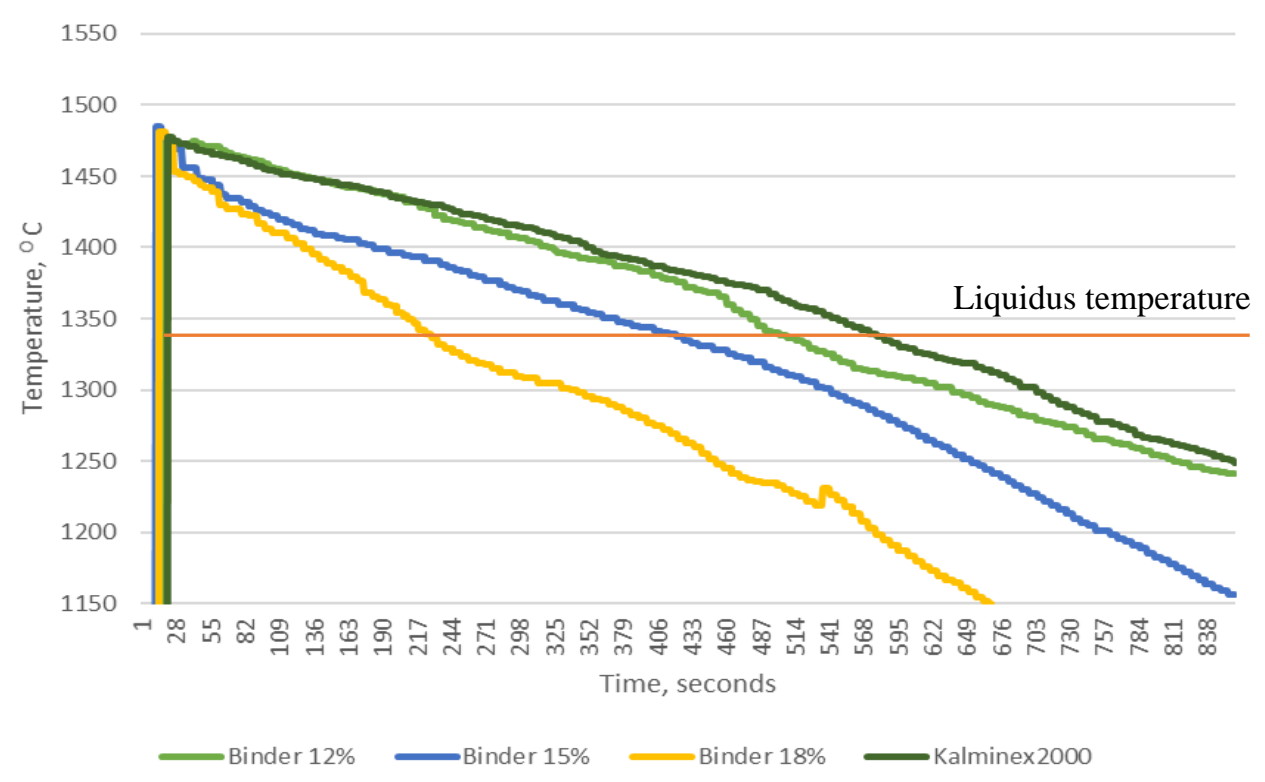

Figure 4 Cooling rate of GX60Cr15 solidification using the rice husk sleeve expressed as a function of binder content

The rice husk sleeve performed best with a binder content of $12 \%$ wt as it maintained the temperature of molten metal above $1340^{\circ} \mathrm{C}$ for up to 511 seconds. The binder content of $15 \%$ wt and $18 \%$ wt kept the molten steel above liquidus temperature for 409 seconds and 237 seconds, respectively. These results indicate that the binder content has a significant influence on temperature retardation as shown it determines the amount of rice 
husk ash that forms after the burning process, which contributes to the insulating effect. The lower the binder content of a sleeve, the more rice husk ash formed. The characteristics of rice husk ash include good refractoriness (which depends primarily on its alkali oxides content), high porosity, light weight and bulkiness (Kapur, 1980). The porosity of the rice husk sleeve enhances its insulating capability (Kaviany, 1995) to prevent heat loss and prolong the solidification time, as illustrated in Figure 5. This is because the porosity of the sleeve is related to its compression strength. For example, a compression strength of 16 $\mathrm{kg} / \mathrm{cm}^{2}$ resulted from a porosity of $68 \%$ (Kapur, 1980).

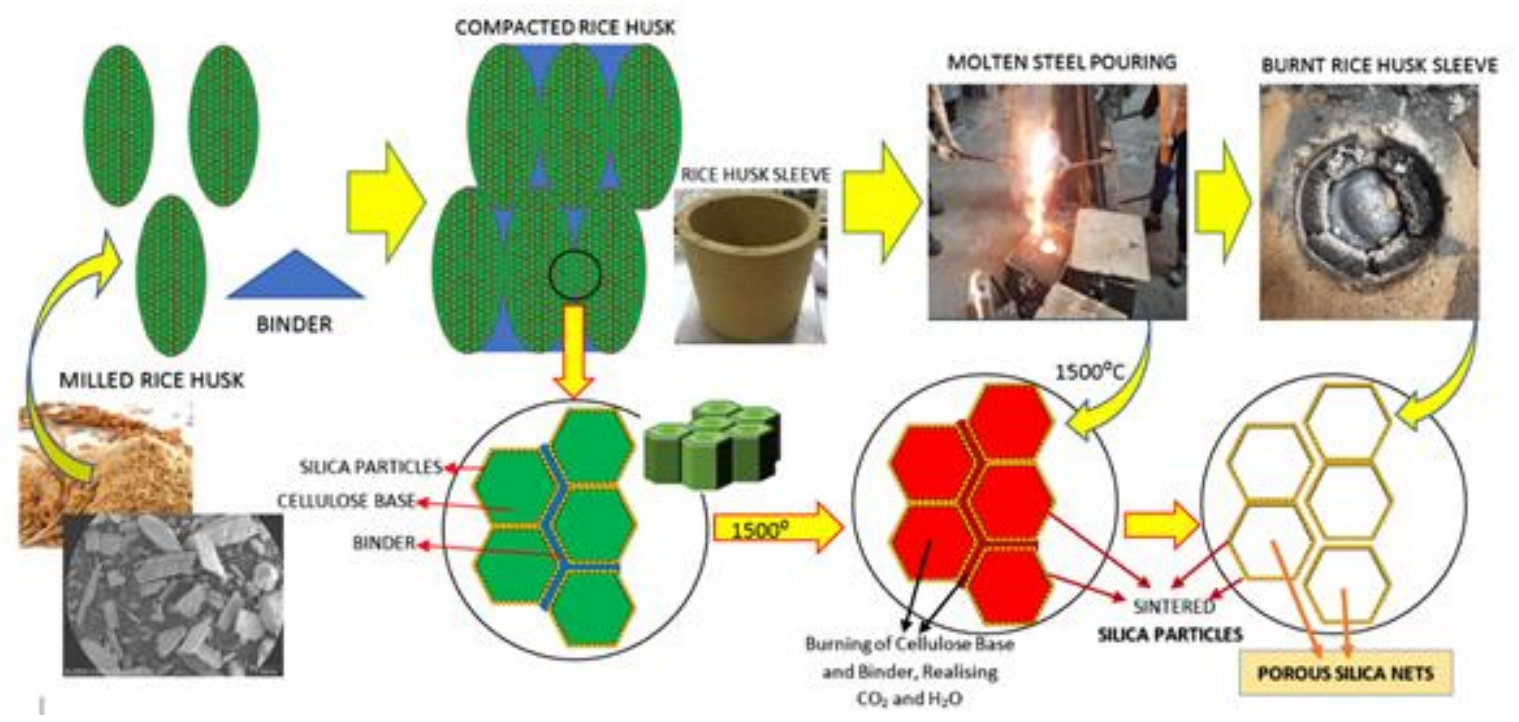

Figure 5 Illustration of porous silica net formation as a result of burning the rice husk sleeve

Table 4 The modulus of sand riser and sleeve in relation to retardation time

\begin{tabular}{|c|c|c|c|c|}
\hline $\begin{array}{l}\text { Sand riser Dimensions } \\
\text { Diameter }(\varnothing) \mathrm{mm} \text {, } \\
\text { Height }(\mathrm{H}) \mathrm{mm} \\
\end{array}$ & $\begin{array}{c}\text { Volume }\left(\mathrm{mm}^{3}\right) \\
\text { Heat releasing } \\
\text { area }\left(\mathrm{mm}^{2}\right) \\
\end{array}$ & $\begin{array}{l}\text { Modulus, } \\
\mathrm{cm}\end{array}$ & $\begin{array}{l}\text { Retardation } \\
\text { time, s }\end{array}$ & $\begin{array}{l}\text { Modulus extension } \\
\text { factor (MEF) } \\
=\text { sand/sleeve } \\
\end{array}$ \\
\hline$\varnothing 80 \mathrm{~mm}, \mathrm{H} 80 \mathrm{~mm}$ & $444 / 32.2$ & 1.38 & 215 & \\
\hline$\varnothing 90$ mm, H 90 mm & $625 / 40.5$ & 1.54 & 278 & \\
\hline$\varnothing 100 \mathrm{~mm}, \mathrm{H} 100 \mathrm{~mm}$ & 867 / 50.4 & 1.72 & 342 & \\
\hline$\varnothing 110 \mathrm{~mm} 110 \mathrm{~mm}$ & 1.164 / 61.3 & 1.90 & 409 & \\
\hline$\varnothing 130 \mathrm{~mm} 120 \mathrm{~mm}$ & $1.592 / 755$ & 2.1 & 436 & \\
\hline$\varnothing 140 \mathrm{~mm}, 140 \mathrm{~mm}$ & 2.155 / 923 & 2.33 & 454 & \\
\hline$\varnothing 140 \mathrm{~mm}, 150 \mathrm{~mm}$ & 2.474 / 1.013 & 2.44 & 527 & \\
\hline $\begin{array}{l}\text { Rice husk sleeve binder } \\
12 \% \mathrm{wt}\end{array}$ & $443.677 / 32.2$ & 1.38 & 511 & $2.33 / 1.38=1.69$ \\
\hline $\begin{array}{l}\text { Rice husk sleeve binder } \\
15 \% \mathrm{wt}\end{array}$ & 443.677 / 32.2 & 1.38 & 409 & $1.90 / 1.38=1.46$ \\
\hline $\begin{array}{l}\text { Rice husk sleeve binder } \\
18 \% \text { wt }\end{array}$ & 443.677 / 32.2 & 1.38 & 237 & $1.54 / 1.38=1.12$ \\
\hline KALMINEX 2000 & 443.677 / 32.2 & 1.38 & 579 & $2.44 / 1.38=1.77$ \\
\hline
\end{tabular}

The performance of an exothermic sleeve is also quantified by measuring the MEF, which represents the increase in the modulus of the riser (Rao, 2013). The higher the MEF value, the smaller the dimensions of the sleeve. The MEF calculation is presented in Table 4 , where the standard modulus of a sand riser is determined as 1.38. As Figure 6 demonstrates, the binder content influenced the MEF results. A binder content of $12 \mathrm{wt} \%$, 
$15 \mathrm{wt} \%$, and $18 \mathrm{wt} \%$ produced MEF values of $1.12,1.38$, and 1.69 , respectively. With a binder content of $12 \mathrm{wt} \%$, the rice husk sleeve has an MEF value close to that of a commercial sleeve (KALMINEX 2000) and can, therefore, be classified as an exothermic sleeve.

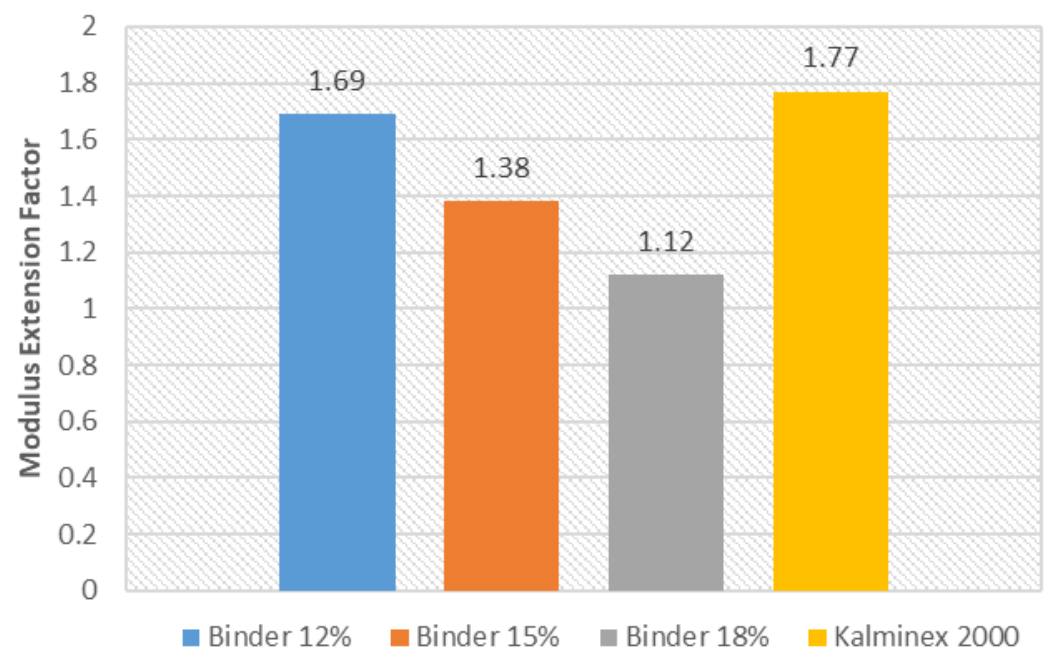

Figure 6 Modulus extension factor of the sleeves

The feeding efficiency of the rice husk sleeve can be simulated by taking a binder content of $12 \mathrm{wt} \%$ and an MEF value of 1.69 and following the calculation steps in Equations 2 to 4 below (The Foundry and Steel Castings Sectional Committee, 2009).

Modulus of the sleeve $(\mathrm{Ms})=(\mathrm{D} \times \mathrm{H}) /(\mathrm{D}+4 \mathrm{H})$

Equivalent modulus of the sand riser $\left(\mathrm{M}_{\mathrm{sr}}\right)=\mathrm{MEF}_{\text {sleeve }} \times \mathrm{M}_{\mathrm{s}}$

Feeding efficiency of rice husk sleeve $=\left(\mathrm{V}_{\mathrm{sr}} / \mathrm{V}_{\mathrm{s}}\right) \mathrm{x} 100 \%$

First, the modulus of the sleeve $\left(\mathrm{M}_{\mathrm{s}}\right)$ is calculated using Equation 2, where D (diameter) is $8 \mathrm{~cm}$, and $\mathrm{H}$ (height) is $8 \mathrm{~cm}$. The $\mathrm{M}_{\mathrm{s}}$ obtained is $1.6 \mathrm{~cm}$ and the $\mathrm{M}_{\mathrm{sr}}$ is $2.704 \mathrm{~cm}$. The real volume of the sand riser $\left(V_{s r}\right)$ is $1940 \mathrm{~cm}^{3}$ and the volume of the sleeve $\left(V_{s}\right)$ is $401.92 \mathrm{~cm}^{3}$. Assuming that the sand riser efficiency is $14 \%$, the molten steel supplies $271.60 \mathrm{~cm}^{3}$. Thus, the feeding efficiency of the rice husk sleeve based on the previous equations is $67.58 \%$. Therefore, by using the rice husk sleeve as a riser, the feeding efficiency can be increased to $67.58 \%$.

\section{Conclusions}

Rice husk waste has significant potential for use as a material for a riser sleeve feeding system in steel casting. The MEF calculation generates an MEF value of 1.69, based on which the rice husk sleeve can be classified as an exothermic sleeve. With a binder content of $12 \mathrm{wt} \%$, the rice husk sleeve had good formability, a sufficient compressive strength of 6.9 $\mathrm{kg} / \mathrm{cm}^{2}$, and excellent temperature retardation of during GX60Cr15 solidification. The solidification time of molten metal in the rice husk sleeve can be extended to 511 seconds, which is higher than that of the sand riser (215 seconds). Furthermore, the feeding efficiency of the rice husk sleeve can be increased to approximately $67.58 \%$. In terms of compliance, the main characteristics of the rice husk sleeve comply with the standard specifications of IS 15865:2009 for an exothermic sleeve. Hence, the rice husk sleeve is 
recommended for use in a feeding system for steel casting, where it has the potential to replace existing commercial exothermic sleeves and enhance the value of rice husk waste.

\section{Acknowledgments}

The authors acknowledge POLMAN-Bandung for providing financial support under the Polman research project. We also thank the foundry department for providing facilities.

\section{References}

Auderheide, R.C., Twardowska, H., Showman, R.E., Ashland Inc., 1999. Insulating Sleeve Compositions and Their Uses. United States Patent, Number 5,983,984

Bates, R.B., Ghoniem, A.F., 2013. Biomass Torrefaction: Modeling of Reaction Thermochemistry. Bioresource Technology, Volume 134, pp. 331-340

Dafiqurrohman, H., Surjosatyo, A., Gibran, F.R., 2016. Air Intake Modification for Pyrolysis Optimization on Rice Husk Fixed Bed Downdraft Gasifier with Maximum Capacity of 30 Kg/hour. International Journal of Technology, Volume 7(8), pp. 1352-1361

Brown, J., 2000. Foseco Ferrous Foundryman's Handbook. Butterworth-Heinemann, United Kingdom: Foseco International Ltd

Gibran, F.R., Adi, S., Hermawan, A.A., Dafiqurrohman, H., Anggriawan, M.B., Yusuf, N.R., Ma'arif, S., 2018. Optimization of Fixed Bed Downdraft Reactor for Rice Husk Biomass Gasification using Secondary Air Intake Variation. International Journal of Technology, Volume 9(2), pp. 390-399

Idamayanti, D., Purwadi, W., Ruskandi, C., Rivan, 2015. Pemanfaatan Aluminium Dross Sebagai Exothermic Sleeve untuk Meningkatkan Efisiensi Pengecoran Baja (Utilization of Aluminum Dross as Exothermic Sleeve to Improve Steel Casting Efficiency). In: Seminar Nasional Teknik Mesin 10. Surabaya: Universitas Kristen Petra

Kapur, P.C., 1980. Thermal Insulations from Rice Husk Ash, an Agricultural Waste. Ceramurgia International, Volume 6(2), pp. 75-78

Kaviany, M., 2012. Principles of Heat Transfer in Porous Media. New York: Springer Science \& Business Media

Lim, J.S., Manan, Z.A., Alwi, S.R.W., Hashim, H., 2012. A Review on Utilisation of Biomass from Rice Industry as a Source of Renewable Energy. Renewable and Sustainable Energy Reviews, Volume 16(5), pp. 3084-3094

Maiti, S., Dey, S., Purakayastha, S., Ghosh, B., 2006. Physical and Thermochemical Characterization of Rice Husk Char as a Potential Biomass Energy Source. Bioresource Technology, Volume 97(16), pp. 2065-2070

Midea, A.C., Burns, W., Schneider, M., Wagner, I., 2007. Advanced Thermo-physical Data for Casting Process Simulation the Importance of Accurate Sleeve Properties. Giessereiforschung, Volume 59(1), pp. 34-43

Miki, M., 2002. Foundry Exothermic Assembly. United States Patent, Number 6,372,032

Purwadi, W., Idamayanti, D., Ruskandi, C., Kamal, J., 2016. Effect of Shape Variation on Feeding Efficiency for Local Exothermic-insulating Sleeve. In: AIP Conference Proceedings, Volume 1778(030017), pp. 1-7

Quispe, I., Navia, R., Kahhat, R., 2017. Energy Potential from Rice Husk through Direct Combustion and Fast Pyrolysis: A Review. Waste Management, Volume 59, pp. 200-210

Rao, P.N., 2013. Manufacturing Technology. $4^{\text {th }}$ Edition, Volume 1. USA: Tata McGraw-Hill Education 
Said, M.M., John, G.R., Mhilu, C.F., 2014. Thermal Characteristics and Kinetics of Rice Husk for Pyrolysis Process. International Journal of Renewable Energy Research, Volume 4(2), pp. 275-278

Schäfer, J., 2011. Innovative Feeder Systems. Casting Plant \& Technology, Volume 3, pp. 3437

The Foundry and Steel Castings Sectional Committee, 2009. Exothermic and Insulating Sleeves for Use in Foundries. IS 15865. Bureau of Indian Standard, India

Tiwari, S., Pradhan, M.K., 2017. Effect of Rice Husk Ash on Properties of Aluminium Alloys: A Review. Materials Today: Proceedings, Volume 4(2), pp. 486-495

Unrean, P., Fui, B.C.L., Rianawati, E., Acda, M., 2018. Comparative Techno-economic Assessment and Environmental Impacts of Rice Husk-to-Fuel Conversion Technologies. Energy, Volume 151, pp. 581-593

Wang, X., Lu, Z., Jia, L., Chen, J., 2016a. Physical Properties and Pyrolysis Characteristics of Rice Husks in Different Atmosphere. Results in Physics, Volume 6, pp. 866-868

Wang, X., Lv, W., Guo, L., Zhai, M., Dong, P., Qi, G., 2016b. Energy and Exergy Analysis of Rice Husk High-temperature Pyrolysis. International Journal of Hydrogen Energy, Volume 41(46), pp. 21121-21130

Williams, T.J., Hardin, R.A., Beckermann, C., 2015. Characterization of the Thermophysical Properties of Riser Sleeve Materials and Analysis of Riser Sleeve Performance. In: Proceedings of the $69^{\text {th }}$ SFSA Technical and Operating Conference, Paper No. 5.9, pp. 128 